\title{
Effects of topical budesonide on epithelial restitution in vivo in guinea pig trachea
}

\author{
Jonas S Erjefält, Ingrid Erjefält, Frank Sundler, Carl G A Persson
}

\begin{abstract}
Background - Continuous epithelial shedding and restitution processes may characterise the airways in diseases such as asthma. Epithelial restitution involves several humoral and cellular mechanisms that may potentially be affected by inhaled anti-asthma drugs. The present study examines the effect of a topical steroid on epithelial restitution in vivo in the guinea pig.

Methods - The airway epithelium was mechanically removed from well defined areas of guinea pig trachea without surgery and without damage to the basement membrane or bleeding. An anti-inflammatory dose of budesonide (1 mg) was administered repeatedly to the tracheal surface by local superfusion 24 hours before, at ( 0 hours), and 24 hours after the denudation. Migration of epithelial cells, formation of a plasma exudation-derived gel, and appearance of luminal leucocytes were recorded by scanning electron microscopy. Cell proliferation was visualised by bromodeoxyuridine immunohistochemistry and tissue neutrophils and eosinophils by enzyme histochemistry.
\end{abstract}

Results - Immediately after creation of the denuded zone ciliated and secretory cells on its border dedifferentiated, flattened out, and migrated speedily (mean (SE) $2 \cdot 3$ $(0 \cdot 3) \mu \mathrm{m} / \mathrm{min})$ over the basement membrane. After 48 hours the entire denuded zone ( $800 \mu \mathrm{m}$ wide) was covered by a tightly sealed epithelium; at this time increased proliferation was observed in new and old epithelium and subepithelial cells. Budesonide had no detectable effect on epithelial dedifferentiation, migration, sealing, or proliferation. Immediately after denudation and continuously during the migration phase plasma was extravasated creating a fibrinous gel rich in leucocytes, particularly neutrophils, over the denuded area. Budesonide had no effect on either the gel or the leucocyte density. Conclusions - These observations suggest that topical glucocorticoids may not interfere with a fast and efficient restitution of the epithelium in the airways.

(Thorax 1995;50:785-792)

Keywords: airways, glucocorticoids, epithelial restitution.

Epithelial repair or restitution occurs in healthy airways and may be extensive in a disease such as asthma. ${ }^{1-3}$ Both in vivo and in vitro approaches have been used in experimental studies of the re-epithelialisation process. Animal studies carried out between the 1950s and early 1980s have established that the repair of a severely damaged airway mucosa involves several phases including migration of epithelial secretory cells, proliferation, and differentiation. ${ }^{4-7}$ Due to the methods used, the immediate phase of repair could not be examined in these studies. The damage to the basement membrane and the resultant bleeding also made it difficult to extrapolate the findings to events occurring in association with simple epithelial shedding. Recent cell culture studies have been able to demonstrate epithelial cell migration after removal of epithelial cells in vitro, ${ }^{89}$ but the relevance of the cell culture data to the in vivo situation is not known.

In an attempt to mimic non-haemorrhagic shedding an in vivo technique has been developed whereby the epithelium is gently removed from a well defined area $(\sim 800 \mu \mathrm{m}$ wide) of the guinea pig trachea leaving the basement membrane intact. ${ }^{1011}$ Immediately after epithelial removal in this model both ciliated and secretory cells from the intact remaining epithelium dedifferentiate, flatten out, and migrate over the denuded basement membrane. (A contribution of basal cells in this migration process is likely but has not yet been shown.) The early migration rate $(\sim 2 \mu \mathrm{m} / \mathrm{min})$ is more than 20 times faster than that observed in cell culture studies. ${ }^{8}$ Migration occurs in close association with a plasma-derived fibronectin-fibrin gel that is also rich in leucocytes. The gel is created shortly after denudation and covers the basement membrane until a new tight epithelium has been established. After denudation neutrophils are rapidly recruited to the denuded area and the gel. ${ }^{1012}$ In addition, eosinophils, which are normally present within the guinea pig mucosa, infiltrate the gel. Within 8-15 hours the entire denuded area becomes covered by a flat epithelium in which the epithelial barrier has been re-established by the formation of cell junctions. This migration and seaming phase is followed by a phase of intense proliferation. Within five days the newly formed epithelium is normally differentiated with ciliated, secretory, and basal cells. ${ }^{111}$ Based on these observations we have suggested that shedding, even of clusters of epithelial cells, may be an important airway defence mechanism and that plasma and leucocytederived factors may contribute to a speedy and efficient restitution in vivo.

The present study was performed to determine whether topical glucocorticoids affect re-epithelialisation in vivo. Glucocorticoids 
are widely used in the treatment of asthma, particularly by the inhaled route. ${ }^{13}$ The experimentally demonstrated effects of glucocorticoids include many physiological and pharmacological actions on epithelial cells, ${ }^{1415}$ infiltrating leucocytes, ${ }^{16-19}$ and the microcirculation. $^{2021}$ Hence, in theory glucocorticoids could have effects on the epithelial repair process. We present here the effect of topical budesonide given daily for three days starting one day before the denudation, and have determined whether this drug interferes with the "acute" phase of epithelial restitution when a new tight epithelial lining is re-established in the denuded zone. In particular, we have examined gross changes in the rate of the re-epithelialisation, the formation of a plasma-derived gel, the accumulation of leucocytes, and the increased epithelial and subepithelial proliferation.

\section{Methods \\ ADMINISTRATION OF ANAESTHETICS AND TRACHEAL SUPERFUSIONS \\ Male Dunkin-Hartley guinea pigs $(n=27$, $500 \mathrm{~g}$, from Möllegaard, Denmark) fasted for 3-4 hours were anaesthetised with a 3:2 mixture of ketamine $(50 \mathrm{mg} / \mathrm{ml})$ and xylazine $(20 \mathrm{mg} /$ $\mathrm{ml})$ intramuscularly $(1 \mathrm{ml} / \mathrm{kg})$. For intra- tracheal mucosal superfusions of solutions guinea pigs were inclined to a $45^{\circ}$ position (head up) and a thin plastic catheter (OD $0.61 \mathrm{~mm}$ ) was introduced via the mouth and placed into the tracheal lumen about $0 \cdot 5-1 \mathrm{~cm}$ below the larynx. During mucosal superfusion (at the rate of $20 \mu 1 / \mathrm{min}$ ) the catheter was connected to a Microinjector (Carnegie Med- ical, Sweden) as previously described. ${ }^{22}$ This technique is a non-traumatic way of restricting the administration of solutes to the large tracheobronchial airways in guinea pigs. ${ }^{23}$}

\section{MUCOSAL ADMINISTRATION OF BUDESONIDE}

The tracheal mucosa was superfused with budesonide for five minutes. A suspension of micronised budesonide $(10 \mathrm{mg} / \mathrm{ml})$ in CMC vehicle $(0 \cdot 75 \%$ sodium carboxyl methyl cellulose and $0.65 \% \mathrm{NaCl}$ ) was used. Budesonide was administered 24 hours before and at 0 and 24 hours after epithelial removal. Control animals received $100 \mu \mathrm{l}$ CMC vehicle. After superfusion the catheter was removed and the animals were kept in the tilted position for an additional five minutes.

\section{REMOVAL OF THE EPITHELIUM}

Guinea pigs were anaesthetised as described above and placed in a supine position. ${ }^{22} \mathrm{~A}$ specially designed steel probe was gently moved into the tracheal lumen down to the carinal region. By applying a slight pressure a longitudinal strip (800-1000 $\mu \mathrm{m}$ width) of the epithelium was removed along the dorsal side of the trachea. Animals $(n=3$ at each time point) were analysed before (non-de-epithelialised controls) and at 10 minutes, and two, eight, and 48 hours after de-epithelialisation. This technique does not cause bleeding or structural damage to the underlying basement membrane. ${ }^{1011}$ In order to examine cell proliferation induced by epithelial removal non-de-epithelialised controls and all animals examined at 48 hours after epithelial removal were injected intraperitoneally with $10 \mathrm{mg} / \mathrm{kg}$ bromodeoxyuridine (BrdU, Sigma, St Louis, USA) one hour before termination of the experiment.

TERMINATION OF THE EXPERIMENT AND SAMPLE PROCESSING

Animals were anaesthetised with an intraperitoneal injection of pentobarbitone $(60 \mathrm{mg}$ / $\mathrm{ml} ; 5 \mathrm{ml} / \mathrm{kg}$ ). The thorax was opened and the animal was exsanguinated by an incision in the still bleeding heart. The trachea was rapidly excised and placed in a petri dish, rinsed gently with $0.9 \% \mathrm{NaCl}$ and cut into segments. For scanning electron microscopic examination one segment $(1 \mathrm{~cm}$ in length) was cut out from each animal $1-2 \mathrm{~cm}$ from the cranial end. Two segments (taken at $2-2 \cdot 5$ and $2 \cdot 5-3 \mathrm{~cm}$ from the cranial end) were used for histochemical and immunohistochemical studies. For high resolution light microscopy one segment was cut out at $0 \cdot 8-1 \mathrm{~cm}$ from the cranial end. Tracheal segments for histochemical and immunohistochemical examination were immersed in Stefanini's buffer ( $2 \%$ formaldehyde and $0 \cdot 2 \%$ picric acid in $0.1 \mathrm{M}$ phosphate buffer, $\mathrm{pH}$ $7 \cdot 2$ ) overnight, rinsed several times in buffer (Tyrode buffer supplemented with $10 \%$ sucrose), frozen in mounting medium (Tissuetech, Miles, USA), and stored at $-70^{\circ} \mathrm{C}$ until examination. Tracheal tubes from the same animal were mounted in a "standing" position on the same mounting stub so that examination of two different tracheal regions (separated by $5 \mathrm{~mm}$ ) were examined on each slide.

\section{SCANNING ELECTRON MICROSCOPY}

Tracheal segments were cut immediately along the ventral side and stretched out on Sylgard coated petri dishes using micro needles. The luminal surface was gently rinsed with PBS buffer ( $\mathrm{pH} \mathrm{7 \cdot 4)}$ and immediately subjected to fixation in a PBS buffer containing $1 \%$ glutaraldehyde and 3\% formaldehyde for two hours. Stretched tracheas were examined in a bright field microscope for any sign of bleeding. In some samples where a gel covered the deepithelialised zone a part of this gel was gently removed using a pair of forceps so that examination of the underlying, denuded surface could be performed. Specimens were rinsed thoroughly in PBS ( $3 \times 20 \mathrm{~min})$ and dehydrated through a series of ethanol $(50 \%, 75 \%, 96 \%$, and $99 \%$ ethanol, $3 \times 15$ minutes at each concentration). Samples were subjected to critical point drying using carbon dioxide as the transitional fluid, gold coated and examined with a Philips 515 scanning electron microscope. The presence of a supramembranal gel on the denuded zone was used as an indication of plasma exudation. By using our technique to de-epithelialise the trachea we have shown that the gel matrix represents extravasated plasma proteins including fibrinogen and fibronectin. ${ }^{10}$ 
HIGH RESOLUTION LIGHT MICROSCOPY

After fixation overnight (in the same fixative as that used for scanning electron microscopy), post-fixation in $1 \%$ osmium tetroxide for one hour, and dehydration in graded acetone solutions the specimens were embedded in Polarbed 812 . Plastic sections $(1 \mu \mathrm{m})$ were cut on an LKB MK ultratome and stained with toluidine blue.

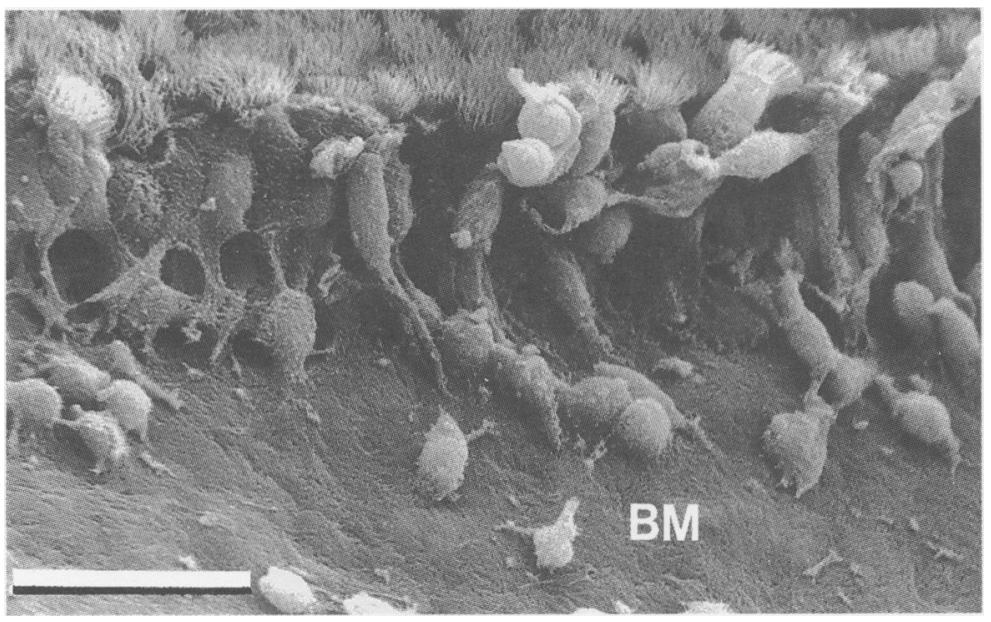

Figure 1 Scanning electron micrograph of the denuded zone immediately after epithelial removal. Note the sharp edge between the denuded and intact basement membrane (BM) and the remaining pseudostratified, columnar epithelium. Scale bar $=50 \mu \mathrm{m}$.
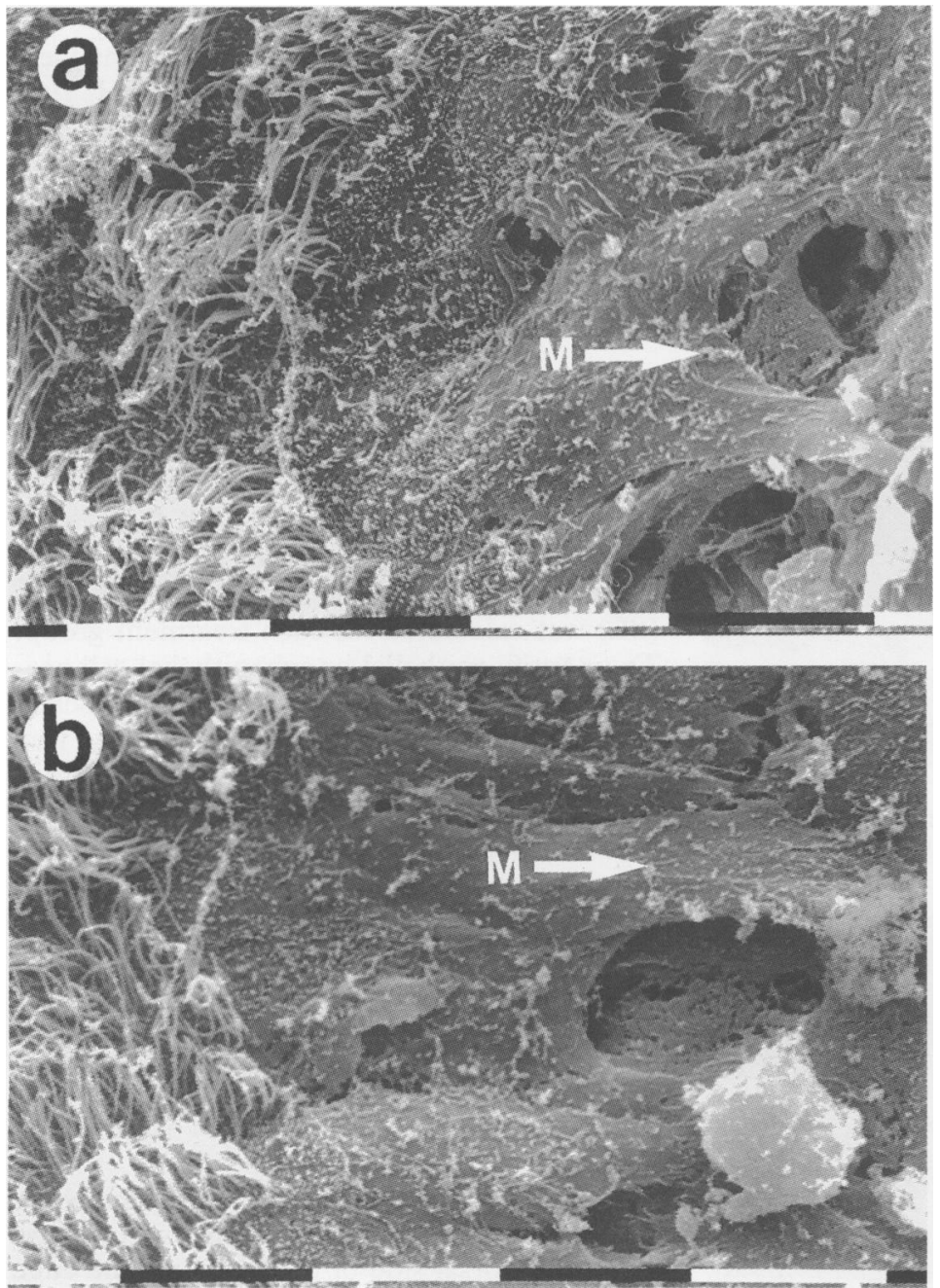

Figure 2 Scanning electron micrographs demonstrating the initial migration at 10 minutes after de-epithelialisation in (a) control and (b) budesonide-treated animals. Note the flat "pseudopodial" morphology of the migrating epithelial cells $(M)$. The arrows demonstrate the direction of the migration. Scale bars $=10 \mu \mathrm{m}$.
MIGRATION

The initial migratory rate at 10 minutes after epithelial removal was calculated from scanning electron micrographs. At eight points $(1 \mathrm{~mm}$ apart) the distance between the original wound edge and the front of the new migrating epithelium was estimated and the mean distance for each animal calculated. The migration rate $(\mu \mathrm{m} / \mathrm{min})$ was expressed as mean (SE) values, $\mathbf{n}=3$ in each treatment group.

\section{CELL PROLIFERATION}

Cells undergoing mitosis were detected by immunohistochemical identification of DNAincorporated bromodeoxyuridine, BrdU. ${ }^{24}$ Tracheas were sectioned in a cryostat (perpendicular to the mucosal surface, $10 \mu \mathrm{m}$ ) and the slides allowed to air dry before being placed in $1 \mathrm{M} \mathrm{HCl}$ at $56^{\circ} \mathrm{C}$ for 30 minutes. Sections were then exposed to the primary antibodies in an appropriate dilution (1:20) overnight at $+4^{\circ} \mathrm{C}$. After thorough rinsing in phosphate buffered saline (PBS) $+0 \cdot 25 \%$ triton X-100 samples were incubated with fluorescein isothiocyanate (FITC)-labelled secondary antibodies for one hour at room temperature. After rinsing in PBS $+0.25 \%$ triton $\mathrm{X}-100$ the sections were mounted in PBS:glycerine (1:1) and then examined in a fluorescence microscope. The primary antibody used was a monoclonal antibody against BrdU (code M744, Dako, Copenhagen, Denmark). ${ }^{24}$ As secondary antibody an FITC-labelled goat antimouse IgG antibody (Jackson, West Grove, Pennsylvania, USA, dilution 1:80) was used. No staining was found in control sections using incubation with only secondary antibodies or normal goat serum.

\section{CYANIDE RESISTANT PEROXIDASE ACTIVITY}

Eosinophils were detected by histochemical staining of cyanide resistant eosinophil peroxidase (EPO). ${ }^{2526}$ Briefly, cryosections ( $7 \mu \mathrm{m}$, cut perpendicular to the mucosal surface) were placed in Tris- $\mathrm{HCl}$ buffer $(\mathrm{pH} \mathrm{7.6)}$ for two minutes and then incubated for seven minutes in room temperature in the same buffer supplemented with 3,3-diaminobenzidine tetrahydrochloride $(75 \mathrm{mg} / 100 \mathrm{ml}$, Sigma, St Louis, USA), $3 \% \mathrm{H}_{2} \mathrm{O}_{2}(0.3 \mathrm{ml} / 100 \mathrm{ml})$, and $\mathrm{NaCN}$ $(50 \mathrm{mg} / 100 \mathrm{ml})$. Slides were washed in PBS buffer, counterstained with haematoxylin, and mounted in Kaiser's medium (Merck, Darmstadt, Germany). Eosinophils were easily identified by their dark brown reaction product. The specificity of this reaction for EPO has recently been evaluated in guinea pigs. ${ }^{26}$

\section{TISSUE NON-SPECIFIC ALKALINE PHOSPHATASE} ACTIVITY

Alkaline phosphatase is a constituent of secondary granules of mature neutrophils. ${ }^{27}$ In the present study neutrophils were identified by a combination of morphological criteria, ${ }^{28}$ EPO histochemistry, and tissue non-specific alkaline phosphatase (TNAP) enzyme histochemistry. ${ }^{27} 29$ Briefly, cryosections $(7 \mu \mathrm{m})$ were subjected to EPO staining (as described above), 

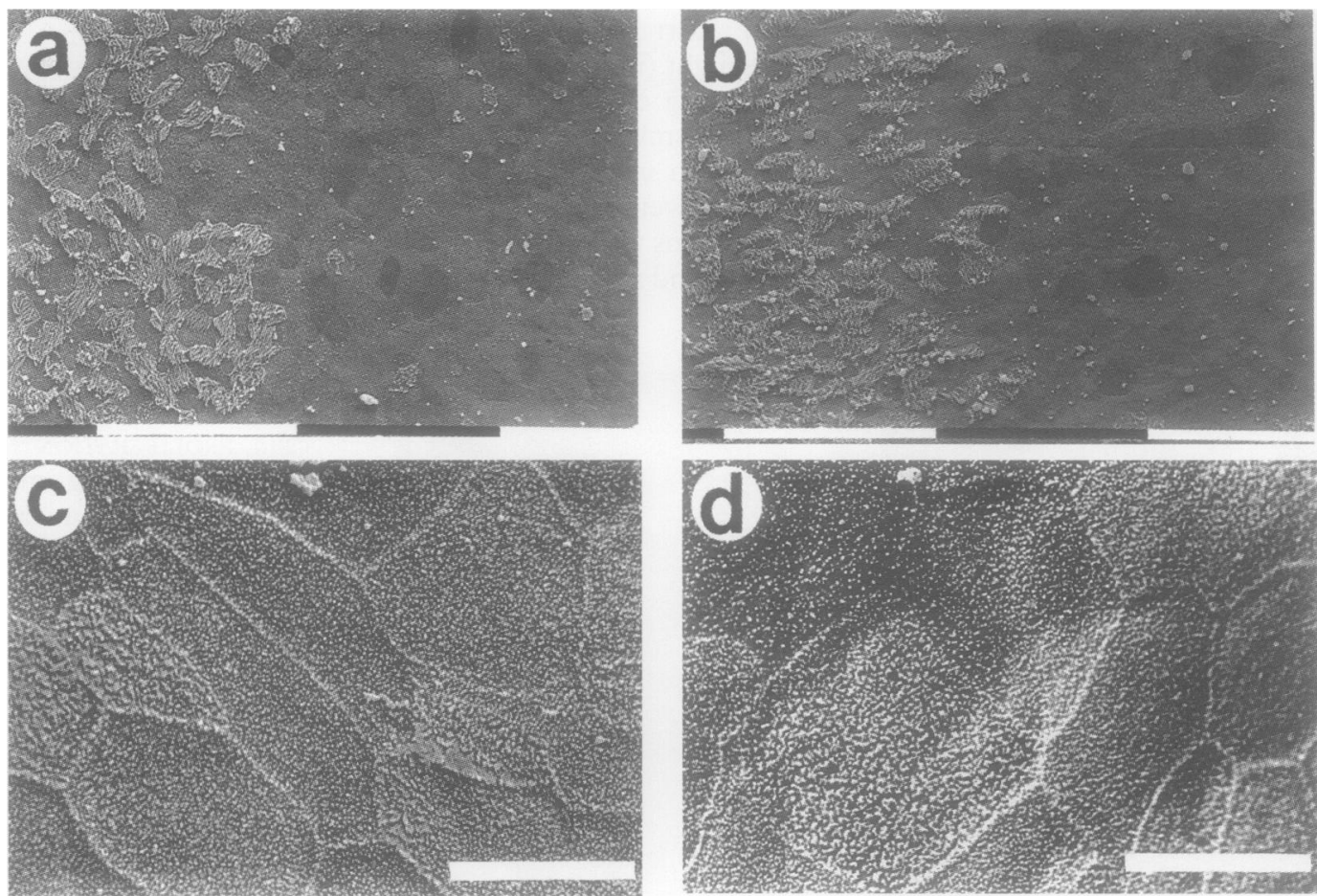

Figure 3 Scanning electron micrographs of the denuded zone 48 hours after de-epithelialisation in control $(a$ and $c)$ and budesonide-treated ( $b$ and d) animals. At this time point the denuded zone is totally covered by a new poorly differentiated epithelium (right in $a$ and $b$ ). Higher magnification of the surface of the new epithelium reveals that the epithelial seams have been established through regular cell-cell ridges ( $c$ and $d$ ). Transmission electron microscopical examination of these cell-cell ridges shows regular tight junction formations. ${ }^{11}$ Scale bars: $a$ and $b=100 \mu m, c$ and $d=$ $10 \mu \mathrm{m}$.

rinsed in a Tris- $\mathrm{HCl}$ buffer $(\mathrm{pH} 7 \cdot 6)$ and then incubated for five minutes in a Tris- $\mathrm{HCl}$ buffer (pH 9.0) containing $0 \cdot 1 \%$ naphthol AS-BI phosphate (substrate, Sigma) and $0 \cdot 1 \%$ fast
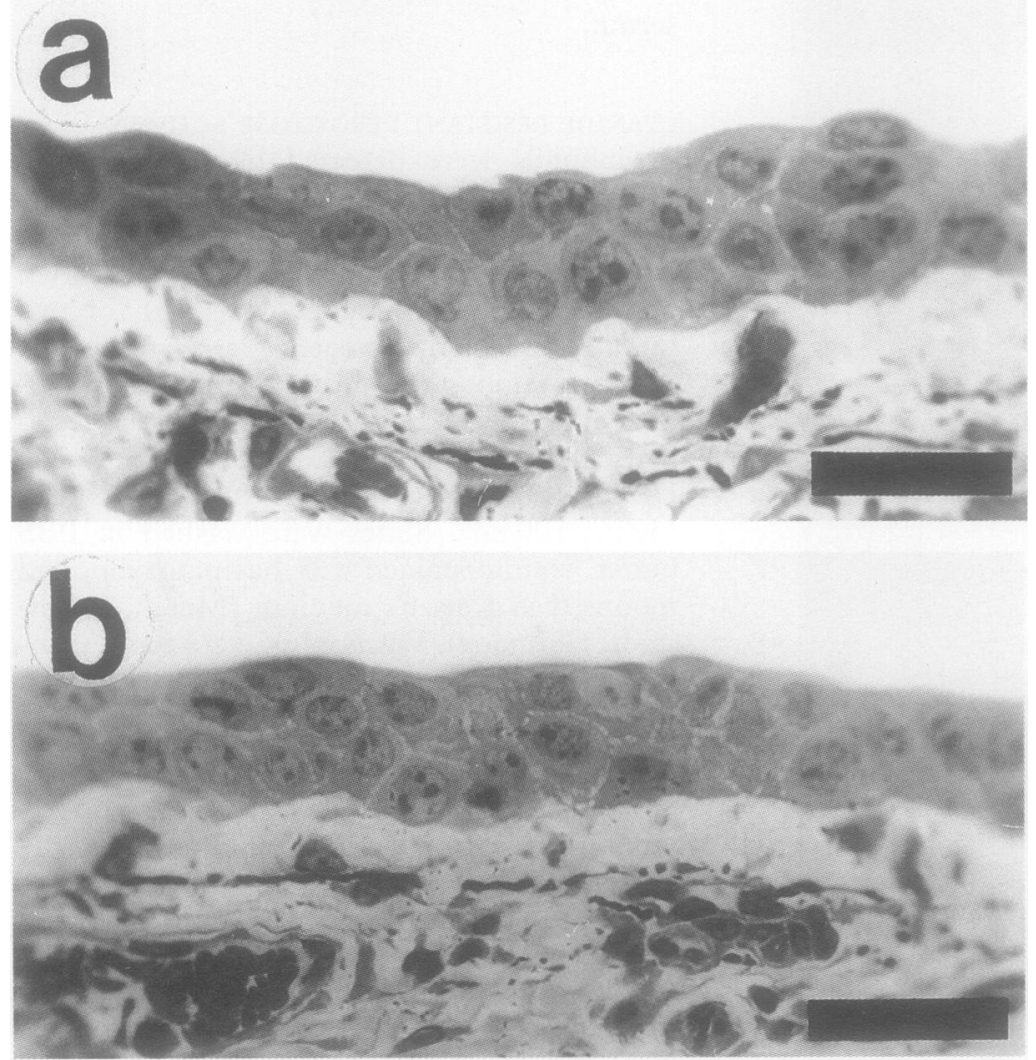

Figure 4 Light micrographs illustrating the new epithelium that covers the denuded area 48 hours after epithelial removal. The new epithelium consists of 2-3 layers of undifferentiated epithelial cells in both (a) vehicle-treated and (b) budesonide-treated animals (toluidine blue stained $1 \mu \mathrm{m}$ sections). Scale bars $=30 \mu \mathrm{m}$. red (azo dye, TR-salt, Sigma). Sections were then briefly rinsed in Tris buffer $(\mathrm{pH} 7 \cdot 6)$, counterstained with toluidine blue, and mounted in Kaiser's medium. Neutrophils were identified by bright field microscopy as small cells with polymorph nuclei displaying EPO-negative and TNAP-positive histochemical reaction.

\section{QUANTIFICATION AND DATA ANALYSIS}

For quantification of eosinophils or neutrophils two tracheal regions (three sections per region), separated by $5 \mathrm{~mm}$, were used from each animal. The total number of leucocytes was counted in each tracheal section and the mean (SE) was calculated for each treatment group. To quantify epithelial or subepithelial cell proliferation the total number of BrdU-labelled cell nuclei was counted in each section. Two tracheal regions (two sections per region) separated by $5 \mathrm{~mm}$ were used from each animal. All data were expressed as mean (SE). To calculate significance levels between treatment groups Wilcoxon Mann-Whitney's non-parametric test was used throughout the study. Probabilities of $<0.05$ were used as the generally accepted level of statistical significance for differences between mean values.

\section{Results}

Immediately after the denudation manoeuvre a denuded zone, $800-1000 \mu \mathrm{m}$ wide, was created along the dorsal side of the trachea. The edge between the denuded but intact basement membrane and the remaining epithelium was distinct and the epithelial lining at the edge had the characteristic morphology of a pseudo- 


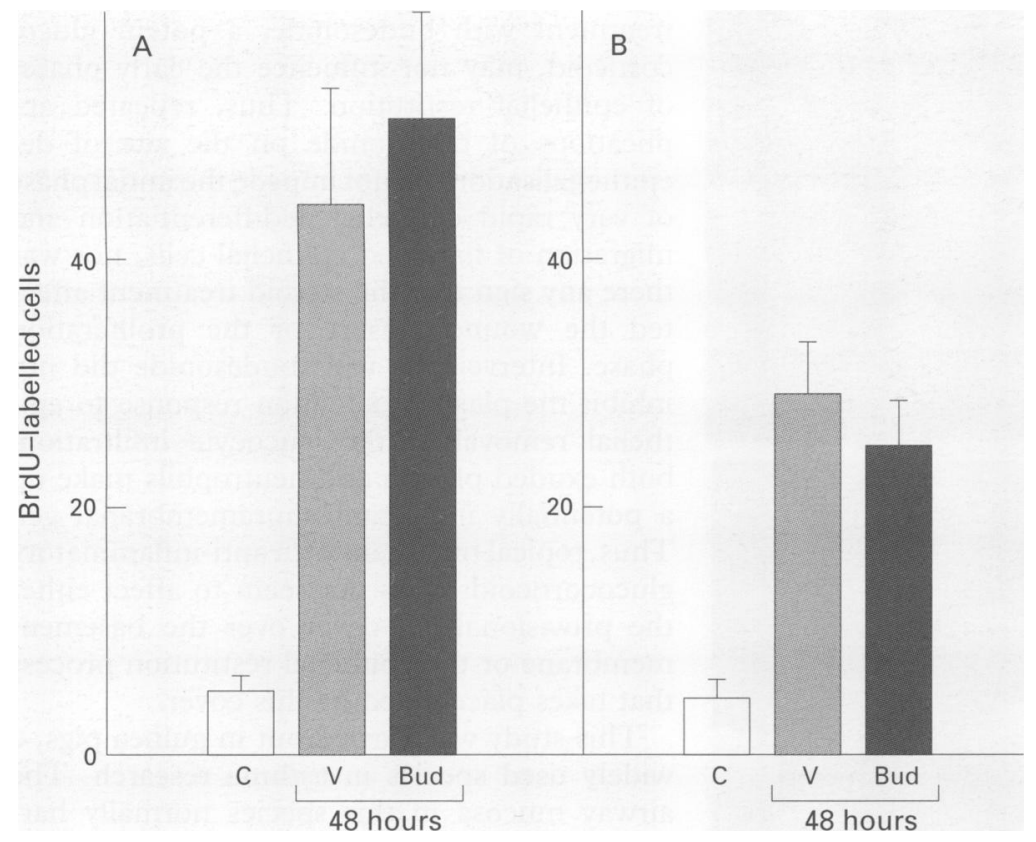

Figure 5 Cell proliferation in $(A)$ the epithelium and $(B)$ the subepithelial tissue in nonde-epithelialised controls $(C)$ and vehicle-treated $(V)$ or budesonide-treated animals 48 hours after epithelial removal. The data are presented as mean and SE values of total numbers of BrdU-positive cell nuclei.
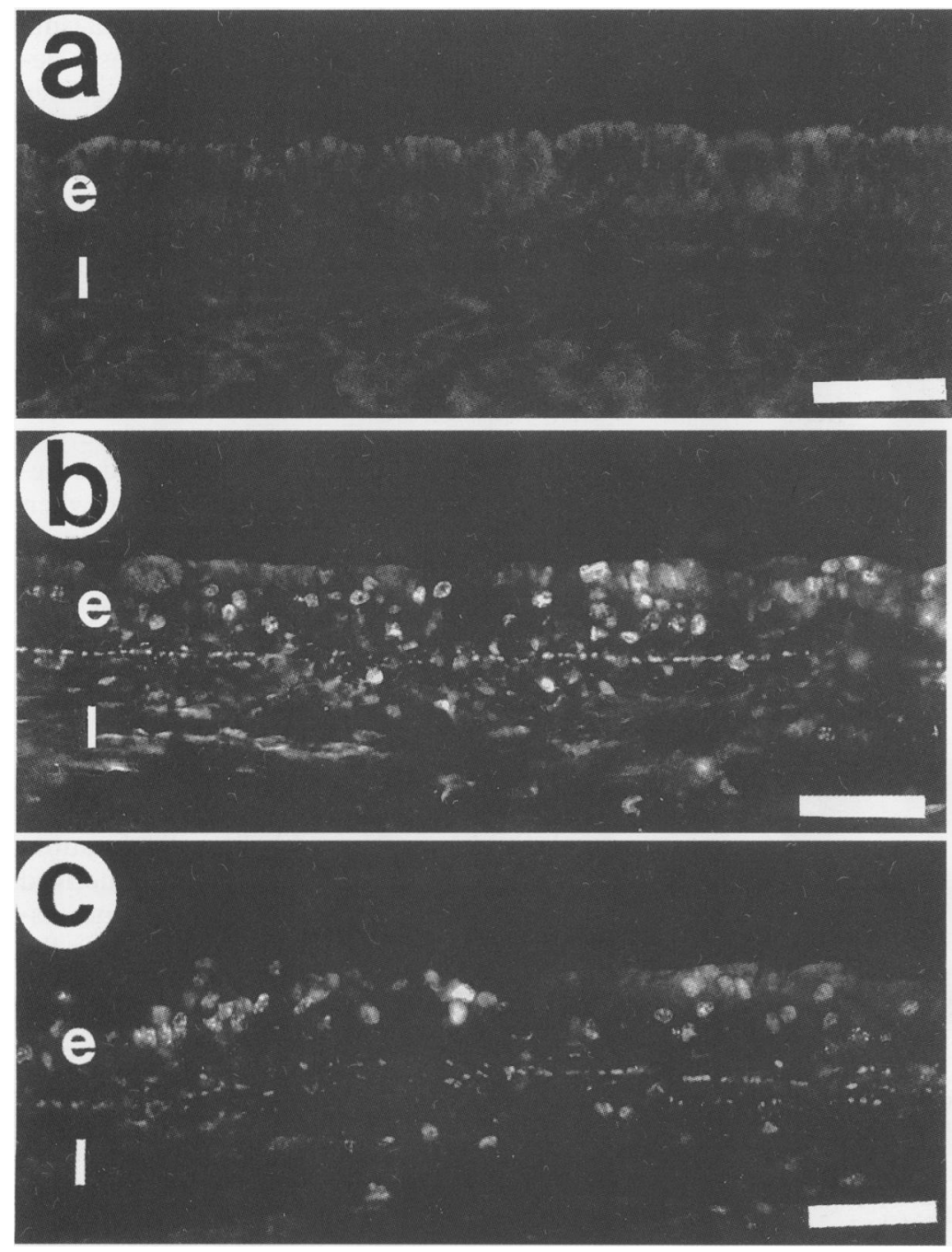

Figure 6 Proliferating cells in (a) non-de-epithelialised controls and in the denuded area 48 hours after epithelial removal in (b) vehicle-treated and (c) budesonide-treated animals. Proliferating cells were visualized by immunohistochemical staining of nucleusincorporated BrdU. In the normal epithelial lining the mitotic activity is low. At 48 hours after epithelial removal a high density of proliferating epithelial cells is present in the new epithelium in both vehicle-treated and steroid-treated tracheas. Note that proliferating non-epithelial cells are also present in both de-epithelialised groups. $e=$ epithelium, $l=$ lamina propria. Scale bars: $a=70 \mu \mathrm{m}, b$ and $c=50 \mu \mathrm{m}$. stratified columnar epithelium (fig 1). Histochemical examination and scanning electron and light microscopy of vehicle-treated animals confirmed our previous results on dedifferentiation, migration, and proliferation of epithelial cells, as well as plasma exudation and leucocyte traffic. ${ }^{10-12}$

\section{MIGRATION OF EPITHELIAL CELLS}

Within 10 minutes ciliated and secretory epithelial cells at the wound margin flattened and migrated over the denuded basement membrane. Neither the morphology of migrating epithelial cells (fig 2) nor the initial speed of migration were affected by the budesonide treatment. The initial migration speed, measured at 10 minutes after denudation, was $2 \cdot 3$ $(0 \cdot 29)$ and $2 \cdot 1(0.34) \mu \mathrm{m} / \mathrm{min}$ in vehicle-treated and budesonide-treated animals, respectively. In all animals examined in both treatment groups the denuded area was totally covered by a new epithelium with closely connected cell-cell borders by 48 hours after de-epithelialisation (fig 3). The new epithelium consisted of 2-3 layers of epithelial cells with flat cuboidal morphology as revealed by light microscopy (fig 4).

\section{CELL PROLIFERATION}

In sections from non-de-epithelialised controls no or only a few scattered BrdU-immunoreactive epithelial or subepithelial cells were detected (fig 5). Forty eight hours after deepithelialisation a clear increase in the number of BrdU-immunoreactive cells was observed in vehicle-treated animals, both in the epithelium $(p<0.05)$ and subepithelial tissue $(p<0.05)$, (figs 5 and 6). The budesonide treatment did not affect this increase in cell proliferation either in the epithelium or subepithelial tissue (figs 5 and 6).

PLASMA EXUDATION: FORMATION OF A PLASMA-DERIVED GEL

Scanning electron and light microscopy of vehicle-treated animals confirmed our previous results. ${ }^{1011}$ As assessed at two and eight hours after de-epithelialisation a gel, rich in extracellular matrix fibres and leucocytes, covered the de-epithelialised zone (fig 7). Budesonide treatment had no detectable effect on this gel formation (fig 7).

\section{TRAFFICKING OF INFLAMMATORY CELLS}

The de-epithelialisation was followed by a significant increase in tissue neutrophils (fig 8A). ${ }^{10}$ Budesonide did not affect the numbers of tissue neutrophils during the course of the re-epithelialisation. Denudation was also followed by a gradual decline in the numbers of tissue eosinophils already present in the guinea pig mucosa (fig 8B), ${ }^{10}$ but again budesonide had no significant effect on eosinophil numbers after de-epithelialisation. 

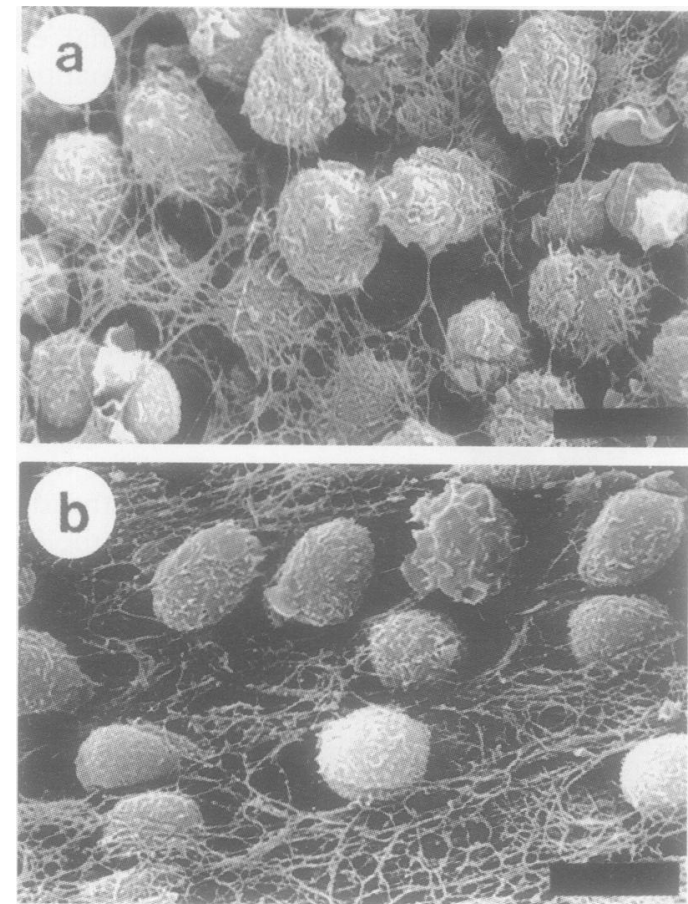

Figure 7 Scanning electron micrographs of the gel surface at two hours after epithelial removal in (a) control and (b) budesonide-treated animals. A rich network of extracellular matrix fibres and a dense infiltration of leucocytes is present in both groups. Scale bars $=10 \mu \mathrm{m}$.
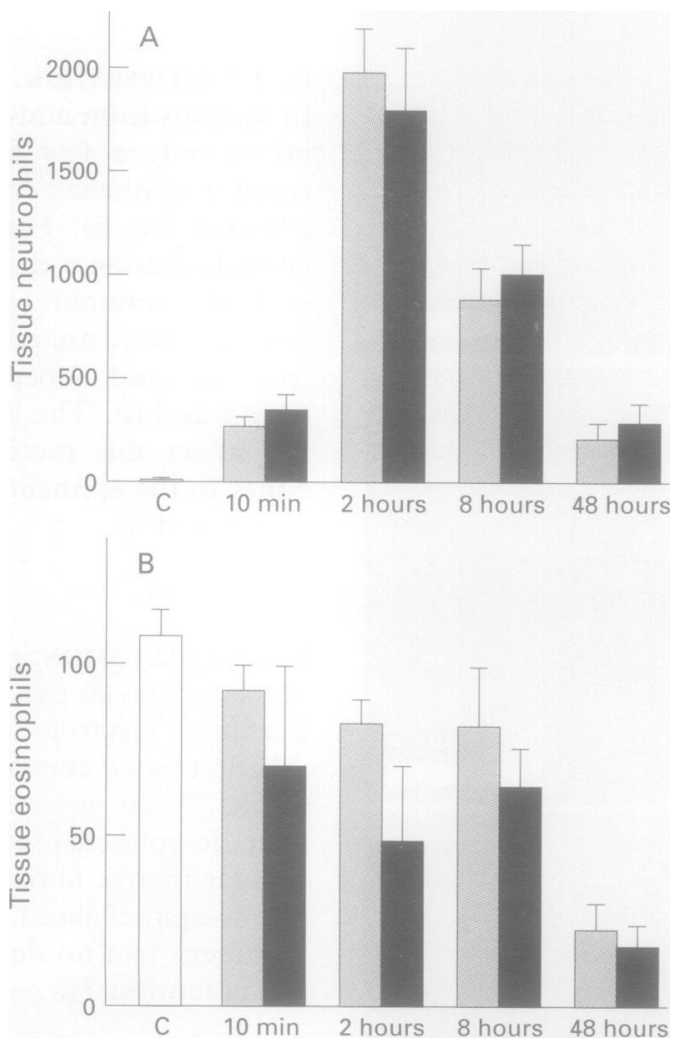

Figure 8 Numbers of $(A)$ tissue neutrophils and (B) eosinophils in the trachea in non-de-epithelialised controls (C) and after epithelial removal in vehicle-treated ( $)$ or budesonide-treated $(\square)$ animals. The data are presented as mean and SE values of total numbers of eosinophils or neutrophils per section.

\section{Discussion}

The present observations confirm our previously reported data on re-epithelialisation of a denuded tracheal basement membrane in vivo $^{1011}$ and show, in addition, that topical treatment with budesonide, a potent glucocorticoid, may not influence the early phases of epithelial restitution. Thus, repeated applications of budesonide on the site of deepithelialisation did not impede the initial phase of very rapid epithelial dedifferentiation and migration of flattened epithelial cells, nor was there any sign that the steroid treatment affected the wound closure or the proliferation phase. Intervention with budesonide did not inhibit the plasma exudation response to epithelial removal or the leucocyte infiltration; both exuded plasma and neutrophils make up a potentially important supramembranal gel. Thus, topical treatment with anti-inflammatory glucocorticoids does not seem to affect either the provisional gel cover over the basement membrane or the epithelial restitution process that takes place aided by this cover.

This study was carried out in guinea pigs, a widely used species in asthma research. The airway mucosa in this species normally harbours eosinophils. ${ }^{1030}$ Andersson et $a l^{31}$ have shown that $0.8 \mathrm{mg}$ budesonide given by intratracheal instillation 20 hours before challenge inhibits the antigen-induced bronchial anaphylaxis in sensitised guinea pigs. Moreover, late phase inflammatory exudation of plasma induced by allergen challenge is dose dependently inhibited by pretreating the guinea pig airways with only a single topical administration of budesonide (0.3-1 mg) just before challenge using the same technique for tracheal superfusion of drugs as in this study. ${ }^{3233}$

Budesonide applied to the airway mucosa is known to have a particularly high affinity and sustained retention in airway tissue. ${ }^{34}$ The drug was given to the animals the day before denudation, allowing time for the onset of glucocorticoid airway effects. The next dose was applied directly to the acutely denuded basement membrane to simulate a condition when the drug is deposited in high concentration on a de-epithelialised surface before the establishment of a protective gel cover. A final dose was given a day later - that is, before the peak of proliferation that occurs $30-70$ hours after the denudation. In this study the proliferation phase was examined 48 hours after denudation. We thus considered that the most important pharmacological actions would concern the initial phase of epithelial cell migration, including the formation of a plasma-derived gel and infiltration of leucocytes, and establishment of a new epithelium including the proliferation phase. No effect of glucocorticoid treatment on the epithelial repair process in airways with a denuded basement membrane occurred, nor were there any detectable changes in the formation of a leucocyte-rich plasma-derived gel. Recently we have shown that the gel, which is rich in "adhesive" plasma proteins - for example, fibrin and fibronectin - serves as a protective and repair-promoting cover over the denuded basement membrane until a new epithelium has been re-established. ${ }^{10}$ This observation is consistent with the demonstration of fibrin deposition at sites of epithelial damage in asthmatic airways..$^{356}$ The lack of glucocorticoid effect in the present 
study suggests that the importance of the gel and its components for rapid and efficient epithelial restitution in vivo may be valid, as suggested previously. ${ }^{10}$

Glucocorticoids may reduce plasma exudation responses by several anti-inflammatory mechanisms. ${ }^{2037}$ In airway disease glucocorticoids may thus inhibit plasma exudation as an index of the global anti-inflammatory efficacy of these drugs. ${ }^{38}$ The plasma exudation response that occurs in non-sensitised guinea pig airways after an acute exposure to toluenediisocyanate is not reduced by pretreatment with budesonide, even when the glucocorticoid is given at high topical and systemic doses. ${ }^{39}$ Similarly, the present study shows that plasma exudation induced by epithelial denudation, which in part may be caused by the removal of an epithelial anti-exudative nitric oxide mechanism, ${ }^{40}$ is not sensitive to inhibition by glucocorticoids. These observations support the notion that glucocorticoids do not inhibit plasma exudation when this response serves primarily a protection, defence, or repair purpose.

The present epithelial insult is followed by prominent accumulation of neutrophils in the gel and lamina propria. ${ }^{12}$ This observation suggests the possibility that part of the increased number of neutrophils in asthmatic mucosa ${ }^{41-43}$ may be due to mechanisms associated with epithelial restitution. Eosinophils already present in the guinea pig mucosa did not accumulate further, but rather exhibited a decline in number after denudation ${ }^{10}$ (this study). Indeed, it is possible that both neutrophils and eosinophils, by releasing growth factors and other agents, may have contributed to the present epithelial repair process that was unimpeded by the presence of budesonide. Prolonged treatment with inhaled steroids in asthma appears to promote the development of a normal, intact epithelial lining. ${ }^{44-46}$ The present animal observations which indicate that epithelial restitution may not be adversely affected by a brief period of treatment with topical steroids are thus consistent with the clinical experience with inhaled glucocorticoids.

This study on guinea pig trachea in vivo has shown that topical anti-inflammatory doses of budesonide may not affect denudation-induced physiological and cellular responses. Accordingly, the plasma exudation gel formation, the leucocyte responses, and epithelial dedifferentiation, migration, sealing, and proliferation were not affected by the drug. We suggest that topical administration of glucocorticoids in the airways does not interfere with the epithelial restitution process that occurs after denudation by epithelial shedding.

This study was supported by grants from the Swedish Medical Research Council (projects 8308 and 4499), Astra Draco, Lund, and the Medical Faculty, University of Lund.

1 Dunnill MS. The pathology of asthma with special reference to the change in the bronchial mucosa. F Clin Pathol 1960 13:27-33.

2 Laitinen L, Heino W, Laitinen A, Kava T, Haahtela T Damage of the airway epithelium and bronchial reactivity in patients with asthma. Am Rev Respir Dis 1985;131 599-606.

3 Bousquet J, Chanez P, Lacoste JY, White R, Vic P, Godhard
P, et al. Asthma: a disease remodeling the airways. Allergy 1992;47:3-11.

4 Correll ON, Beattie J. The characteristics of regeneration of respiratory epithelium. Surg Gynecol Obstet 1956;103: 209-11.

5 Wilhelm DL. Regeneration of tracheal epithelium. $f$ Pathol Bacteriol 1953;LXV:543-50.

6 Lane BP, Gordon R. Regeneration of rat tracheal epithelium after mechanical injury. The relationship between mitotic activity and cellular differentiation. Proc Soc Exp Biol Med 1974; 145:1139-44.

7 Keenan KP, Combs JW, McDowell EM. Regeneration of hamster tracheal epithelium after mechanical injury. I Focal lesions: Quantitative morphologic study of cell proliferation. Virchows Arch (Cell Pathol) 1982;41:193-214.

$8 \mathrm{Zahm} \mathrm{JM}$, Chevillard M, Puchelle E. Wound repair of human surface respiratory epithelium. Am $\mathcal{F}$ Respir Cell Mol Biol 1991;5:242-8.

9 Rickard A, Taylor J, Rennard SI, Spurzem JR. Migration of bovine bronchial epithelial cells to extracellular matrix components. Am $\mathcal{F}$ Respir Cell Mol Biol 1993;8:63-8.

10 Erjefält JS, Erjefält I, Sundler F, Persson CGA. Airway microcirculation-derived factors in epithelial repair. Microvasc Res 1994;48:161-78.

11 Erjefält JS, Erjefält I, Sundler F, Persson CGA. In vivo restitution of airway epithelium. Cell Tissue Res 1995 (in press).

12 Erjefält JS, Erjefält I, Sundler F, Persson CGA. Rapid restitution of airway epithelium in vivo in a milieu of neutrophils, eosinophils and plasma-derived fibrin-fibronectin. Eur Respir f 1994;7(Suppl 18):245s

13 Barnes P, Pedesen S. Efficacy and safety of inhaled corticosteroids in asthma. Am Rev Respir Dis 1993;148:S1-26.

14 Sousa AR, Poston RN, Lane SJ, Nakhosteen JA, Lee TH. Detection of GM-CSF in asthmatic bronchial epithelium and decrease by inhaled corticosteroids. Am Rev Respir Dis 1993;147:1557-61.

15 Borson DB, Gruenert DC. Glucocorticoids induce expression of neutral endopeptidase in transformed human tracheal epithelial cells. Am $\mathcal{f}$ Physiol 1991;260:L82-9.

16 Borish L, Mascali J, Dishick J, Beam WR, Martin RI, Rosenwasser LJ. Detection of alveolar macrophage-derived IL-1 $\beta$ in asthma. Inhibition with corticosteroids. $\mathcal{F}$ Immunol 1992;14:3078-82.

17 Lamas AM, Leon OG, Schleimer RP. Glucocorticoids inhibit eosinophil responses to granulocyte macrophage colony stimulating factor. 7 Immunol $1991 ; 147: 254-9$.

18 Wallen N, Kita H, Weiller D, Gleich GJ. Glucocorticoids inhibit cytokine-mediated eosinophils survival. $f$ Immunol 1991;147:3490-5.

19 Ellul-Micallef R. Glucocorticosteroids. In: Barnes PJ, Rodger IW, Thomson NC, eds. Asthma; basic mechanisms and clinical management. 2nd edn. London: Academic Press, 1992;613-44.

20 Persson CGA, Pipkorn U. Glucocosteroids. In: Waksman BH, ed. 1939-1989: Fifty years of progress in allergy. Basel: Karger, 1990:264-7.

21 Boschetto P, Rogers DF, Fabbri LM, Barnes PJ. Corticosteroid inhibition of airway microvascular leakage. $\mathrm{Am}$ Rev Respir Dis 1991;143:605-9.

22 Erjefält I, Wagner ZG, Strand SE, Persson CGA. A method for studies of tracheobronchial microvascular permeability to macromolecules. $\mathcal{F}$ Pharm Methods 1985;14:275-83.

23 Erjefält I, Persson CGA. Inflammatory passage of plasm macromolecules into airway wall and lumen. 7 Pulmon Pharmacol 1989;2:93-102.

24 Jones HB, Clark AB, Barrass NC. Phenobarbital-induced hepatocellular proliferation: Anti-bromodeoxyuridine and anti-proliferating cell nuclear antigen immunoand anti-proliferating cell nuclear antigen imm

25 Ten RM, Pease LR, McKean DJ, Bell MP, Gleich GJ Molecular cloning of the eosinophil peroxidase. Evidence for the existence of a peroxidase multigene family. $\mathcal{f}$ Exp Med 1989;169:1757-69.

26 Lapa e Silva JR, Bachelet CM, Pretolani M, Baker D, Sheper RJ, Vargaftig B. Immunopathologic alterations in the bronchi of immunized guinea pigs. Am $\mathcal{F}$ Respir Cell Mol Biol 1993;9:44-53.

27 Rosolia DL, McKenna PJ, Gee MH, Albertine KH. Infusion of zymosan-activated plasma affects neutrophil in peripheral blood and bone marrow in sheep. 7 Leuk Biol 1992 52:501-15.

28 Hutson PA, Church MK, Clay TP, Miller P, Holgate ST Early and late-phase bronchoconstriction after allergen challenge of nonanesthetized guinea pigs. Am Rev Respi Dis 1988;137:548-57.

29 Kaplow LS. Leukocyte alkaline phosphatase cytochemistry: applications and methods. Ann NY Acad Sci 1968;155: 911-47.

30 Frew AJ, Moqbel R, Azzawi M, Hartnell A, Barkans J, Jeffrey PK, et al. T-lymphocytes and eosinophils in allergen-induced late-phase asthmatic reactions in the guinea pig. Am Rev Respir Dis 1990;141:407-13.

31 Andersson P, Brange C, Von Kogerer B, Sonmark, Stahre G. Effect of glucocorticosteroid treatment on ovalbumininduced IgE-mediated immediate and late allergic response in the guinea pig. Int Arch Allergy Appl Immunol 1988;87:32-9.

32 Erjefält I, Greiff L, Alkner U, Persson CGA. Allergeninduced biphasic plasma exudation responses in guinea pig large airways. Am Rev Respir Dis 1993;148:694-701.

33 Erjefält I, Persson CGA. Effects of budesonide on allergenand toluine diisocyanate-induced late phase airway exudation of bulk plasma. Am $\mathcal{F}$ Respir Crit Care Med 1995 (in press) 
34 Miller-Larsson A, Brattsand R. Tissue affinity for topical glucocorticoids (GCS) for intact and leaky airways. Allergy 1993;48:90.

35 Jeffrey PK, Wardlaw AJ, Nelson FC, Collins JV, Kay AB Bronchial biopsies in asthma. An ultrastructural, quantitative study and correlation with hyperreactivity. $A m R e$ Respir Dis 1989;140:1745-53.

36 Hirsch SR. The role of mucus in asthma. In: Stein M, ed. New directions in asthma. Illinois: American College of Chest Physicians, 1975:352-63.

37 Schleimer RP. An overview of glucocorticoid antiinflammatory actions. Eur $\mathcal{F}$ Pharmacol 1993;45(Suppl) inflammatory actions. Eur F Pharmacol 1993;45(Suppl):

8 Svensson C, Klementsson H, Andersson M, Pipkorn U, Alkner U, Persson CGA. Glucocorticoid-induced inhibition of mucosal exudation of fibrinogen and bradykinins in seasonal allergic rhinitis. Allergy 1995 (in press)

39 Erjefält I, Persson CGA. Increased sensitivity to toluenediisocyanate (TDI) in airways previously exposed to low doses of TDI. Clin Exp Allergy 1992;22:854-62.

40 Erjefält JS, Erjefält I, Sundler F, Persson CGA. Mucosal nitric oxide may tonically suppress airways plasma exudation. Am f Respir Crit Care Med 1994;150:227-32.

41 Montefort S, Gratziou C, Goulding D, Haskard DO, Howarth PH, Holgate ST, et al. Bronchial biopsy evidence for leukocyte infiltration and upregulation of leukocyte- endothelial cell adhesion molecules 6 hours after local allergen challenges of sensitized asthmatic airways. $\mathcal{f}$ Clin Invest 1994;93:1411-21.

42 Fabbri LM, Boschetto P, Zocca E, Milani G, Pivirotto F, Plebani $M$, et al. Bronchoalveolar neutrophilia during late asthmatic reaction induced by toluene diisocyanate. $A m$ Rev Respir Dis 1987;136:36-42.

43 Sur S, Grotty TB, Kephart GM, Hyma BA, Colby TV, Reed CE, et al. Sudden-onset fatal asthma. A distinct entity with few eosinophils and relatively more neutrophils in the airway submucosa. Am Rev Respir Dis 1993;148 $713-9$.

44 Laitinen LA, Laitinen A, Haahtela T. A comparative study of the effects of an inhaled corticosteroid, budesonide, and a $\beta_{2}$-agonist, terbutaline, on airway inflammation in newly diagnosed asthma: A randomized, double-blind, parallel-group controlled trial. $\mathcal{F}$ Allergy Clin Immunol 1992 90:34-42.

45 Lundgren R, Söderberg M, Hörstedt P, Stenling R. Morphological studies of bronchial mucosal biopsies from asthmatics before and after ten years of treatment with asthmatics before and after ten years of treatr
inhaled steroids. Eur Respir $\mathcal{F} 1988 ; 1: 883-9$.

46 Djukanovic R, Wilson SW, Britten KM, Wilson SJ, Walls $\mathrm{AF}$, Roche WR, et al. Effect of an inhaled corticosteroid on airway inflammation and symptoms in asthma. $A m$ Rev Respir Dis 1992;145:669-74. 